\title{
ACETABULAR OSTEOLYSIS AND MIGRATION IN BIPOLAR ARTHROPLASTY OF THE HIP
}

\author{
FIVE- TO 13-YEAR FOLLOW-UP STUDY \\ KATSUYA NAKATA, KENJI OHZONO, KENSAKU MASUHARA, MINORU MATSUI, \\ KAZUO HIROSHIMA, TAKAHIRO OCHI \\ From Osaka University Medical School and Osaka National Hospital, Japan
}

We have reviewed 65 bipolar arthroplasties of the hip in 55 patients with osteoarthritis secondary to dysplasia. The mean age at operation was 56 years $(42$ to 79$)$ and the mean period of follow-up was 7.2 years $(5.0$ to 13.0$)$.

The average Merle d'Aubigné and Postel score before operation was 10.3 and at final follow-up 15.0. There were excellent or good results in 42 hips $(65 \%)$.

Migration of the outer head was observed in 50 hips $(77 \%)$, most often in the group with a centre-edge angle of less than $0^{\circ}$, an acetabular head index of less than $60 \%$, coverage of the outer head by the original acetabulum of less than $+10^{\circ}$ and after bone grafting of the acetabulum. This migration was progressive in 31 $(62 \%)$ of the 50 hips, with massive osteolysis of the acetabulum in eight. The extent and progression of migration were closely associated with this osteolysis. Four hips required revision for extensive migration of the outer head with destruction of the acetabulum or severe acetabular osteolysis, and nine hips are awaiting revision for failure of the bipolar prosthetic head. The overall failure rate was $18 \%$.

We report major problems after bipolar hip arthroplasty for osteoarthritis secondary to hip dysplasia with progressive migration of the outer head and massive acetabular osteolysis at five years or more after operation.

J Bone Joint Surg [Br] 1997;79-B:258-64

Received 19 August 1996; Accepted after revision 11 October 1996

K. Nakata, MD, Course Student

K. Masuhara, MD, PhD, Associate Professor

M. Matsui, MD, PhD, Assistant Professor

T. Ochi, MD, PhD, Professor and Chairman

Department of Orthopaedic Surgery, Osaka University Medical School,

2-2 Yamadaoka, Suita, Osaka 565, Japan.

K. Ohzono, MD, PhD, Associate Professor

K. Hiroshima, MD, PhD, Professor and Chairman

Department of Orthopaedic Surgery, Osaka National Hospital, 2-1-14

Hoenzaka Chuoku, Osaka 540, Japan.

Correspondence should be sent to Dr K. Nakata.

(C)1997 British Editorial Society of Bone and Joint Surgery 0301-620X/97/27181\$2.00
In 1974 bipolar arthroplasty of the hip was introduced for the management of fractures of the neck and osteonecrosis of the head of the femur. ${ }^{1,2}$ The claimed advantages were reduction of shear stress on the acetabulum because of the inner metal-on-polyethylene bearing, preservation of the acetabular bone stock, and easy conversion to total hip arthroplasty (THA). ${ }^{3-5}$ This type of prosthesis has also been used for osteoarthritis. ${ }^{4-11}$ Migration of the outer head has been reported soon after operation for dysplastic osteoarthritis. ${ }^{5,10,12}$ Extensive migration will lead to limb-length discrepancy, loss of acetabular bone stock, and increased technical difficulty of conversion to THA. ${ }^{12}$ Osteolysis of the acetabulum has recently been reported in association with bipolar hip arthroplasty; this was considered to be an unexpected complication. ${ }^{13}$

We have again reviewed the clinical and radiological outcome of bipolar hip arthroplasties for secondary osteoarthritis of the hip which we reported in a previous study. ${ }^{12}$ We aimed to assess whether migration of the outer head is progressive and whether osteolysis is an 'unexpected' complication.

\section{PATIENTS AND METHODS}

We have reported our early results after 71 bipolar hip arthroplasties carried out on 61 patients for secondary osteoarthritis of the hip from December 1981 to October 1989. ${ }^{12}$ Four hips were revised within five years of operation. Three of them had shown extensive migration of the outer head, followed by breakage of the screws anchoring the bone graft. The other had loosening of the cemented stem. Two patients with single operations have been lost to review, leaving 65 hips in 55 patients with follow-up for 5 to 13 years (mean 7.2). There were 51 women and four men, with a mean age at operation of 56 years (42 to 79). All had osteoarthritis of the hip secondary to dysplasia.

The Bateman universal proximal femoral (UPF) implant (3M, St Paul, Minnesota) was used in 26 hips, the Physiohip system (Kyocera, Kyoto, Japan) in 25 and the Hastings hip prosthesis (Charles Thackray, Leeds, UK) in 14. Between 1981 and 1984 we usually used the Bateman or Hastings hips which have an outer shell of cobalt-chro- 
Table I. Clinical details and radiological profiles of both groups. Values are given as the mean and SEM

\begin{tabular}{llll}
\hline & Grafted & Ungrafted & p value \\
\hline Number of hips (patients) & $28(22)$ & $37(33)$ & -- \\
Age at operation in years & $52.7 \pm 0.8$ & $59.1 \pm 1.7$ & $0.002^{*}$ \\
Weight in kilograms & $53.6 \pm 1.5$ & $53.4 \pm 1.7$ & $0.9^{*}$ \\
Male:female & $2: 20$ & $2: 31$ & $0.8 \dagger$ \\
Duration of follow-up in years & $6.9+0.2$ & $7.4+0.3$ & $0.1^{*}$ \\
Type of component (B:K:H) $\neq$ & $9: 12: 7$ & $17: 13: 7$ & $0.5 \dagger$ \\
Stem fixation (cemented:cementless) & $9: 19$ & $12: 25$ & $0.9 \dagger$ \\
Sharp's angle in degrees & $52.2 \pm 0.9$ & $47.6 \pm 0.7$ & $<0.001^{*}$ \\
Centre-edge angle in degrees & $-23.4 \pm 6.6$ & $+4.9 \pm 2.6$ & $<0.001^{*}$ \\
Acetabular head index $(\%)$ & $40.5 \pm 4.1$ & $57.3 \pm 2.0$ & $<0.001^{*}$ \\
\hline
\end{tabular}

* unpaired Student's $t$-test

$\dagger$ chi-squared test or Fisher's exact probability test

$\ddagger \mathrm{B}$, Bateman UPF prosthesis; K, Kyocera Physio-hip system; H, Hastings hip prosthesis

Table II. Immediate postoperative radiological measurements in both groups. Values are given as the mean and SEM

\begin{tabular}{llll}
\hline & $\begin{array}{l}\text { Grafted } \\
(\mathbf{n = 2 8})\end{array}$ & $\begin{array}{l}\text { Ungrafted } \\
(\mathbf{n = 3 7 )}\end{array}$ & p value \\
\hline Distance to medial wall in $\mathrm{mm}$ & $4.9 \pm 0.6$ & $7.0 \pm 0.5$ & $0.009^{*}$ \\
Coverage by acetabular bone in degrees & $-6.0 \pm 2.9$ & $+17.0 \pm 2.0$ & $<0.001^{*}$ \\
Coverage by grafted bone in degrees & $+41.8 \pm 2.2$ & -- & -- \\
Height of the outer head in $\mathrm{mm}$ & $25.3 \pm 1.6$ & $23.3 \pm 1.0$ & $0.3^{*}$ \\
\hline
\end{tabular}

* unpaired Student's $t$-test

mium alloy, but between 1985 and 1989 we favoured the Kyocera Physio-hip system which has ceramic inner and outer heads. The femoral components were cemented in 24 hips (16 Bateman and 8 Hastings) and not cemented in 41 (10 Bateman, 25 Physio-hip and 6 Hastings).

At operation the hip was exposed through a posterolateral approach in 25 cases and a transtrochanteric approach in 40 . The acetabulum was reamed to the size of the prosthetic head to cover as much of the outer head as possible with sound acetabular bone. The medial wall of the acetabulum was left about $5 \mathrm{~mm}$ thick. When the centre-edge (CE) angle was less than $10^{\circ}$ on the preoperative radiographs a block bone graft was taken from the resected femoral head or iliac crest, ${ }^{12}$ and fixed to the acetabulum with two or three AO cortical screws or ceramic screws. A total of 28 hips was grafted and 37 did not require this.

Table I gives the clinical details of the patients in the grafted and ungrafted groups. On radiographs taken after the operation, we measured the distance from the outer head to the medial wall of the acetabulum, the coverage of the outer head by the original acetabular or grafted bone, and the height of the centre of the outer head in relation to the interteardrop (Table II).

After operation, hip exercises began on the first day, and patients were mobilised non-weight-bearing after one week. Partial weight-bearing began after four weeks in the ungrafted group and after six weeks in the grafted group. Patients were encouraged to increase weight-bearing gradually and progress to full loading after three months. A cane was used in the opposite hand until six months after operation.

Clinical assessment. Hip function was assessed clinically using the Merle d'Aubigné and Postel score, ${ }^{14}$ which gives a maximum of six points for each of the three categories of pain, mobility and gait. We graded 17 or 18 points as excellent, 15 or 16 as good, 13 or 14 as fair, and 12 or less as poor.

Radiological findings. Serial anteroposterior radiographs of the hip and pelvis, centred over the pubis, were used to assess migration of the outer head, loosening of the components and osteolysis of the acetabulum or femur. The extent of migration of the outer head was determined by comparing views taken during the immediate postoperative period and at later dates. A co-ordinate system was established by using the interteardrop line as the abscissa and a line perpendicular to this through the distal edge of the teardrop of the affected hip as the ordinate.

Cemented femoral components were considered to have loosened when migration of the stem or circumferential radiolucent lines between cement and bone were seen. ${ }^{15,16}$ A cementless stem was defined as loose according to the criteria of Callaghan. ${ }^{17,18}$

Statistical analysis. We used the chi-squared test, Fisher's 
exact probability test, contingency table analysis or the unpaired Student's $t$-test for statistical analysis and a $\mathrm{p}$ value of less than 0.05 was considered significant.

\section{RESULTS}

Table III gives details of hip function before and after operation and Table IV the clinical and radiological appearances at the final review.

Migration of the outer head of $3 \mathrm{~mm}$ or more was seen in 50 hips $(77 \%)$, with a mean movement of $6 \mathrm{~mm}$ (0 to 22) at the latest follow-up. The mean migration in the grafted group was $7.0 \mathrm{~mm}$ and in the ungrafted group $5.1 \mathrm{~mm}$ (Table IV). Migration of the outer head occurred in $26(93 \%)$ of the grafted and in $24(65 \%)$ of the ungrafted group (Table IV). At the final review 31 hips $(62 \%)$ showed progressive migration, $17(61 \%)$ in the grafted group (Fig. 1) and 14 (38\%) in the ungrafted group (Fig. 2). Table $\mathrm{V}$ shows the risk factors governing mig- ration, indicating that acetabular osteolysis was a highly significant influence on the progression of prosthetic migration.

There was loosening of the femoral component in ten hips $(15 \%)$, six of which were uncemented. Subsidence of the femoral component was seen in six uncemented stems and one cemented. Complete circumferential radiolucent lines were seen at the cement-bone interface of three stems.

Table III. Pre- and postoperative mean values for hip function according to Merle d'Aubigné and Postel ${ }^{14}$

\begin{tabular}{lllll}
\hline & Pain & Mobility & Gait function & Total \\
\hline Preoperative & 3.2 & 4.4 & 2.7 & 10.3 \\
Postoperative (years) & & & & \\
$\quad 1$ & 5.6 & 5.2 & 3.6 & 14.4 \\
3 & 5.6 & 5.5 & 4.0 & 15.1 \\
5 & 5.8 & 5.4 & 4.0 & 15.2 \\
Final follow-up & 5.6 & 5.5 & 3.9 & 15.0 \\
\hline
\end{tabular}

Table IV. Clinical and radiological results at the final follow-up. Values are given as mean and SEM

\begin{tabular}{lccc}
\hline & $\begin{array}{l}\text { Grafted } \\
(\mathbf{n = 2 8})\end{array}$ & $\begin{array}{l}\text { Ungrafted } \\
(\mathbf{n}=\mathbf{3 7})\end{array}$ & p value \\
\hline $\begin{array}{l}\text { Hip function (Merle d'Aubigné and Postel } \\
\quad \text { Final follow-up (points) }\end{array}$ & $15.1 \pm 0.3$ & $15.1 \pm 0.2$ & $0.9^{*}$ \\
$\quad$ Excellent or good (hips) & $16(57 \%)$ & $24(65 \%)$ & $0.5 \dagger$ \\
Extent of migration in mm & $7.0 \pm 0.8$ & $5.1 \pm 0.6$ & $0.08^{*}$ \\
Migration $\geq 3$ mm (hips) & $26(93 \%)$ & $24(65 \%)$ & $0.008 \dagger$ \\
Progressive migration (hips) & $17(61 \%)$ & $14(38 \%)$ & $0.07 \dagger$ \\
Acetabular osteolysis (hips) & $4(14 \%)$ & $4(11 \%)$ & $0.9 \dagger$ \\
\hline
\end{tabular}

* unpaired Student's $t$-test

$\dagger$ chi-squared test or Fisher's exact probability test

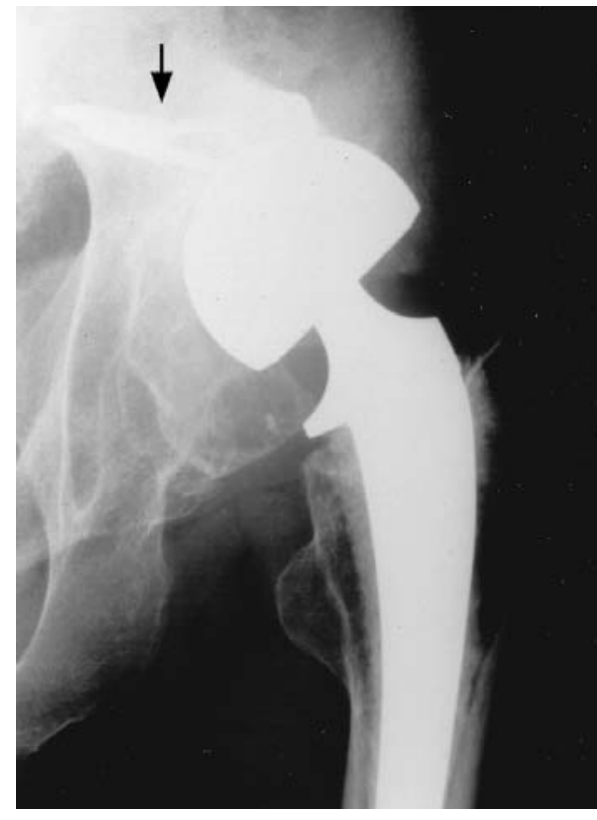

Fig. 1a

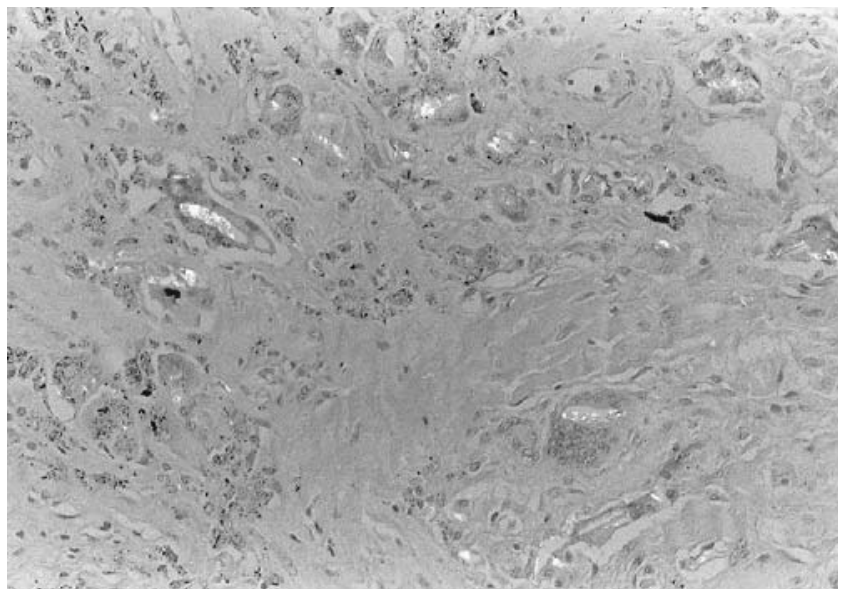

Fig. 1b

Failure of a bipolar prosthesis in the grafted group. Figure 1a - Radiograph six years after operation shows $13 \mathrm{~mm}$ migration of the outer head with invasion of the original acetabulum and the grafted bone and breakage of the screws used to fix the bone graft (black arrow). Figure 1b - Photomicrograph of the pseudocapsule demonstrating granular histiocytes and multinucleated giant cells which have phagocytosed numerous polyethylene and metal particles (haematoxylin and eosin $\times 100$ ). 


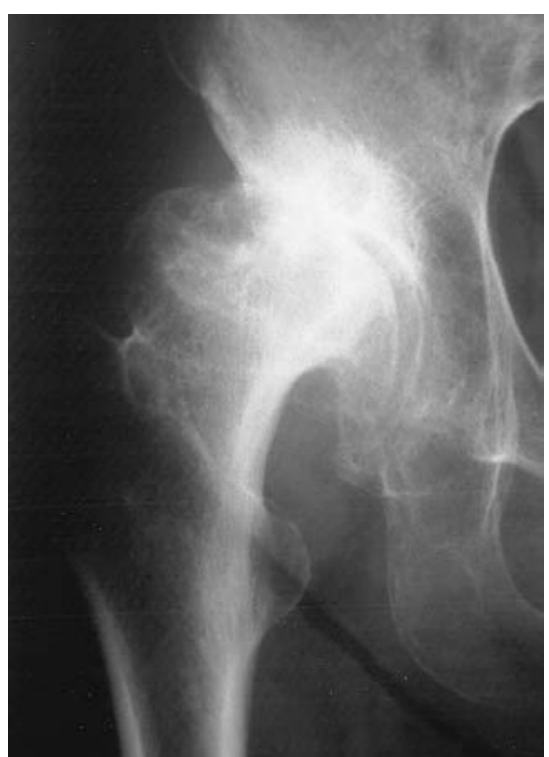

Fig. 2a

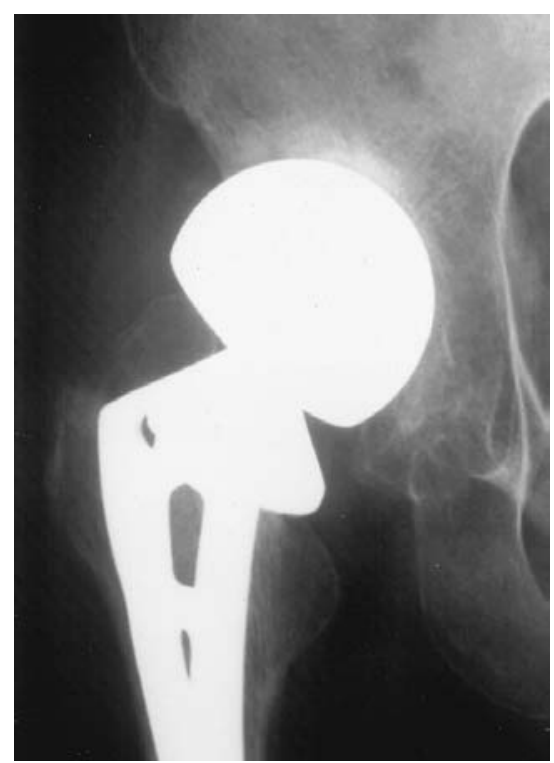

Fig. 2b

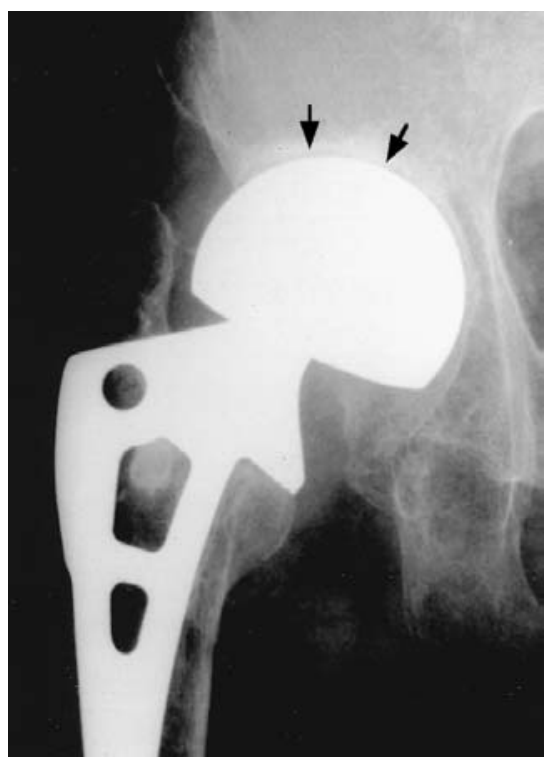

Fig. 2c

Failure of a bipolar prosthesis in the ungrafted group. Figure 2a - Preoperative radiograph showing osteoarthritis secondary to mild hip dysplasia. Figure $2 \mathrm{~b}$ - Bipolar hip arthroplasty was performed without acetabular bone grafting. The outer head appeared to be adequately covered by the original acetabulum. Figure $2 \mathrm{c}$ - Eight years after operation. The head has migrated $9 \mathrm{~mm}$ in a progressive fashion, and there are radiolucent lines (black arrows) at the interface.

Table V. Risk factors for migration of the outer head

\begin{tabular}{|c|c|c|c|c|c|}
\hline \multirow[b]{2}{*}{ Factors } & \multirow[b]{2}{*}{ Number of hips } & \multicolumn{2}{|c|}{ Migration $\geq 3 \mathbf{~ m m}$} & \multicolumn{2}{|c|}{ Progressive migration } \\
\hline & & Yes & p value & Yes & p value* \\
\hline \multicolumn{6}{|c|}{ Age at operation in years } \\
\hline$<55$ & 32 & 25 & 0.8 & 16 & 0.7 \\
\hline$\geq 55$ & 33 & 25 & & 15 & \\
\hline \multicolumn{6}{|l|}{ Gender } \\
\hline Male & 4 & 3 & 0.9 & 2 & 0.9 \\
\hline Female & 61 & 47 & & 29 & \\
\hline \multicolumn{6}{|c|}{ Sharp's angle in degrees } \\
\hline$<50$ & 32 & 24 & 0.7 & 13 & 0.3 \\
\hline$\geq 50$ & 33 & 26 & & 18 & \\
\hline \multicolumn{6}{|c|}{$\mathrm{CE}$ angle in degrees } \\
\hline$<0$ & 32 & 28 & 0.05 & 13 & 0.3 \\
\hline$\geq 0$ & 33 & 22 & & 18 & \\
\hline \multicolumn{6}{|l|}{$\mathrm{AHI}(\%)$} \\
\hline$<60$ & 44 & 37 & 0.05 & 19 & 0.3 \\
\hline$\geq 60$ & 21 & 13 & & 12 & \\
\hline \multicolumn{6}{|c|}{ Distance to medial wall in $\mathrm{mm}$} \\
\hline$<5$ & 27 & 23 & 0.2 & 12 & 0.7 \\
\hline$\geq 5$ & 38 & 27 & & 19 & \\
\hline \multicolumn{6}{|c|}{ Coverage by acetabular bone in degrees } \\
\hline$<+10$ & 30 & 30 & $<0.001$ & 17 & 0.2 \\
\hline$\geq+10$ & 35 & 20 & & 14 & \\
\hline \multicolumn{6}{|c|}{ Coverage by grafted bone in degrees } \\
\hline$<+40$ & 11 & 11 & 0.2 & 6 & 0.8 \\
\hline$\geq+40$ & 17 & 15 & & 10 & \\
\hline \multicolumn{6}{|c|}{ Height of the outer head in $\mathrm{mm}$} \\
\hline$<25$ & 36 & 27 & 0.7 & 14 & 0.1 \\
\hline$\geq 25$ & 29 & 23 & & 17 & \\
\hline \multicolumn{6}{|c|}{ Acetabular bone grafting } \\
\hline Grafted & 28 & 26 & 0.008 & 17 & 0.07 \\
\hline Ungrafted & 37 & 24 & & 14 & \\
\hline \multicolumn{6}{|c|}{ Acetabular osteolysis } \\
\hline Yes & 8 & 8 & 0.1 & 8 & 0.002 \\
\hline No & 57 & 42 & & 23 & \\
\hline
\end{tabular}

* contingency table analysis 
Table VI. Details of eight cases of acetabular osteolysis

\begin{tabular}{|c|c|c|c|c|c|c|c|c|}
\hline \multirow[b]{2}{*}{ Case } & \multirow{2}{*}{$\begin{array}{l}\text { Acetabular } \\
\text { bone grafting }\end{array}$} & \multirow{2}{*}{$\begin{array}{l}\text { Outer } \\
\text { head* }\end{array}$} & \multirow{2}{*}{$\begin{array}{l}\text { Stem } \\
\text { fixation } \uparrow\end{array}$} & \multirow{2}{*}{$\begin{array}{l}\text { Duration of } \\
\text { follow-up (yr) }\end{array}$} & \multicolumn{2}{|c|}{ Migration of outer head } & \multirow{2}{*}{$\begin{array}{l}\text { Revision } \\
\text { surgery }\end{array}$} & \multirow{2}{*}{$\begin{array}{l}\text { Femoral } \\
\text { osteolysis }\end{array}$} \\
\hline & & & & & Extent (mm) & Progressive & & \\
\hline 1 & Yes & B & $\mathrm{C}+$ & 7.8 & 12.0 & Yes & Awaiting & Yes \\
\hline 2 & Yes & B & $\mathrm{C}+$ & 6.4 & 13.0 & Yes & Yes & No \\
\hline 3 & Yes & $\mathrm{H}$ & $\mathrm{C}+$ & 9.5 & 22.0 & Yes & Yes & Yes \\
\hline 4 & Yes & $\mathrm{K}$ & $\mathrm{C}-$ & 7.2 & 4.6 & Yes & No & No \\
\hline 5 & No & B & $\mathrm{C}+$ & 6.0 & 9.5 & Yes & Yes & No \\
\hline 6 & No & $\mathrm{B}$ & $\mathrm{C}+$ & 9.3 & 10.0 & Yes & Awaiting & Yes \\
\hline 7 & No & B & $\mathrm{C}-$ & 9.8 & 8.0 & Yes & No & Yes \\
\hline 8 & No & $\mathrm{K}$ & $\mathrm{C}-$ & 7.0 & 8.0 & Yes & No & No \\
\hline
\end{tabular}

* B, Bateman UPF prosthesis; K, Kyocera Physio-hip system; H, Hastings hip prosthesis $\dagger \mathrm{C}+$, cemented; C-, cementless

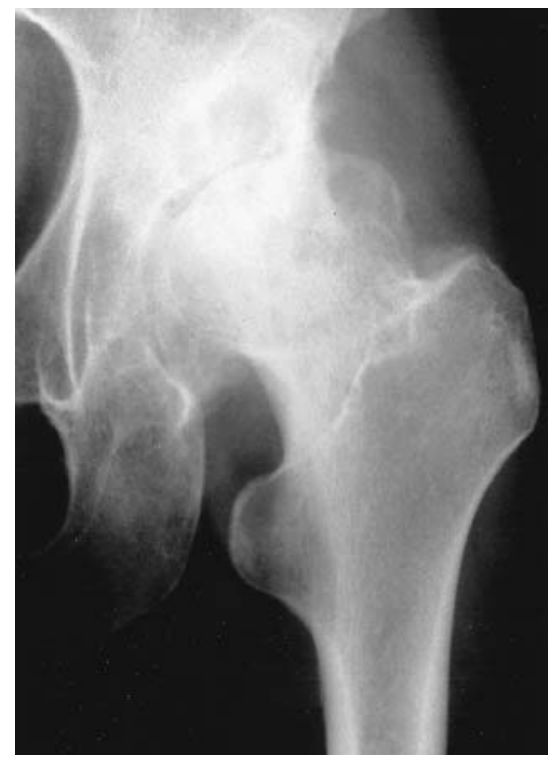

Fig. 3a

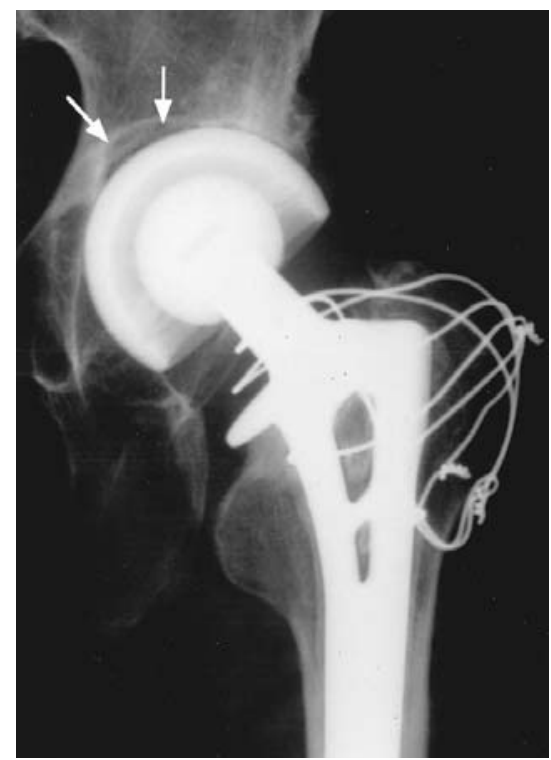

Fig. 3d

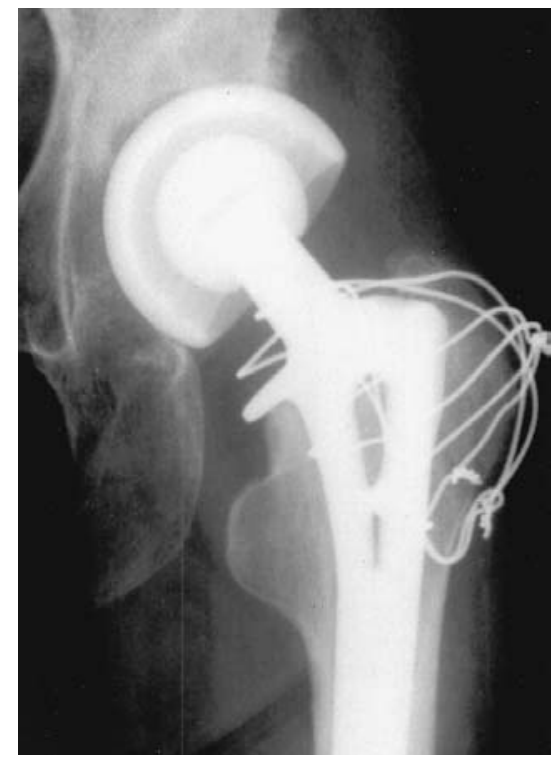

Fig. 3b

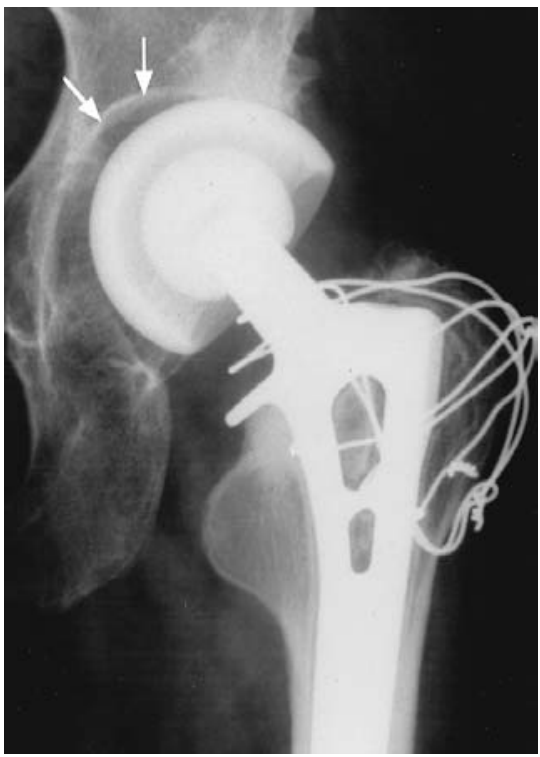

Fig. 3c

Acetabular osteolysis in the ungrafted group. Figure 3a - Preoperative radiograph in a 54-year-old woman. Figure $3 b$ - Bipolar hip arthroplasty without acetabular bone graft. Figure 3c - Massive acetabular osteolysis (white arrows) began to appear between the acetabulum and the outer head at two years after operation. Figure $3 \mathrm{~d}-$ Seven years after operation there is $8 \mathrm{~mm}$ progressive migration with massive acetabular osteolysis (white arrows). 


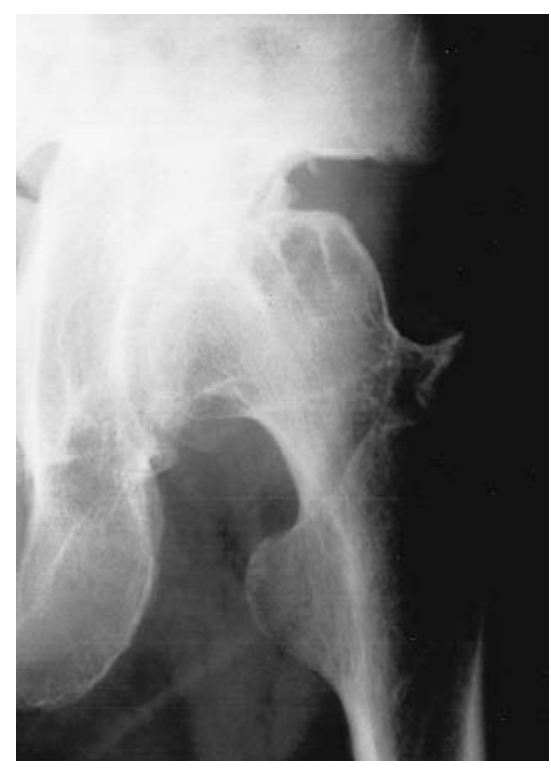

Fig. 4a

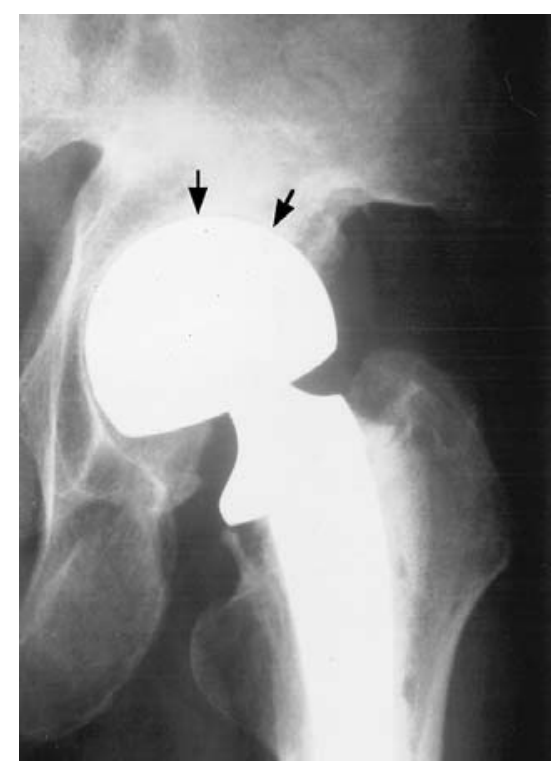

Fig. 4b

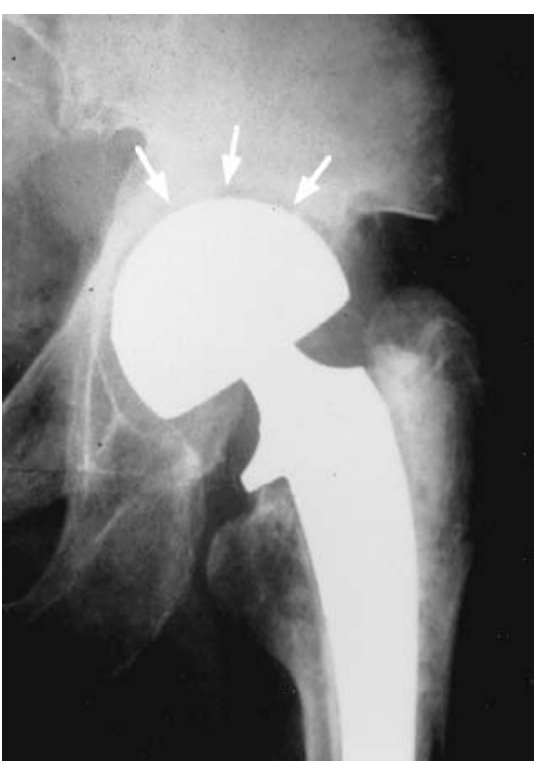

Fig. 4c

Progressive migration of the outer head and acetabular osteolysis after bipolar arthroplasty in the ungrafted group. Figure 4a - Preoperative radiograph showing osteoarthritis secondary to hip dysplasia in a 60 -year-old man. Figure $4 \mathrm{~b}-$ Two years after operation there is a circumferential radiolucent line at the interface between the acetabulum and the outer head (black arrows). Figure $4 \mathrm{c}-$ Progressive migration of the head ( $9 \mathrm{~mm}$ ) was seen during the six years after operation, with extensive acetabular osteolysis (white arrows).

Osteolysis (Table VI). There was massive osteolysis of the acetabular bone in eight hips, four grafted and four ungrafted. The incidence was $12 \%$ overall and $26 \%$ in the 31 hips which showed progressive migration (Table V). The average migration of the eight outer heads with acetabular osteolysis was $10.9 \mathrm{~mm}$ (4.6 to 22.0), all being progressive over six years after operation (Figs 3 and 4). Histological examination of the membrane at the site of the osteolysis excised during revision showed a marked foreign-body reaction (Fig. 1).

Osteolysis was observed around the stem in eight hips (12\%), four cemented and four uncemented. It was present in both the acetabulum and the femur in four hips (Table VI). Revision operations. Revision had been undertaken on four hips (three grafted and one ungrafted) because of failure of the prosthetic head, extensive migration of the outer head followed by breakage of screws used for anchoring bone grafts, or extensive migration of the prosthesis with severe osteolysis of the acetabulum. A further seven hips in the grafted and two in the ungrafted group are awaiting revision, giving an overall rate of failure of $18 \%$. The average migration of the head in these cases was $11.3 \mathrm{~mm}$ (6.4 to 22.0 ). The rims of the polyethylene insert in the revised outer heads showed circumferential wear (cases 2, 3 and 5 in Table VI), which may have been induced by friction between the outer and inner portions.

\section{DISCUSSION}

Since the introduction of the bipolar prosthesis ${ }^{1,2}$ some surgeons have used it as an arthroplasty for osteoarthritis of the hip. ${ }^{4-12}$ Bateman $^{6}$ reported good results in patients with primary osteoarthritis, but the outcome in dysplastic hips was less satisfactory due to early superior migration of the head. $^{4,5,-12}$ We have previously shown excellent or good results in only $50 \%$ of our patients, ${ }^{12}$ with migration in $68 \%$ in spite of the use of bone graft to provide adequate superior cover. Erosion of bone stock makes revision more difficult.

After bipolar arthroplasty for osteoarthritis movement may occur between the inner head and the polyethylene liner, and between the acetabulum and the outer head. ${ }^{3,19}$ The claimed advantage of this prosthesis is a reduction of shear stress on the acetabulum because of the inner metalon-polyethylene bearing. ${ }^{3-5}$ Joint motion, however, may actually increase the shear stress on the acetabulum producing progressive migration of the outer head.

A recent case report suggested that osteolysis of the acetabulum in association with bipolar arthroplasty was a late and unexpected complication, ${ }^{3}$ but we have seen this problem in $12 \%$ of the hips in our series and feel that it constitutes a major problem. Migration was more extensive in patients with osteolysis of the acetabulum, with massive osteolysis in eight (26\%) of 31 hips with progressive migration of the outer head $(\mathrm{p}=0.002)$.

Circumferential radiolucent lines usually appear at the interface between the acetabulum and the outer head within a relatively short period after bipolar hip arthroplasty. ${ }^{5}$ These radiolucent lines may be due to a preactivated fibrous membrane; this can more easily invade at this interface because of the smooth surface of the unfixed outer head and the movement between it and the acetabulum. 
Debris formed by erosion of the polyethylene liner from friction between the outer and inner heads ${ }^{20}$ may activate the interface membrane between the outer head and the acetabulum causing a foreign-body reaction and osteolysis. The major histological feature of our specimens of tissue from the sites of osteolysis was the presence of a foreignbody reaction to polyethylene debris. This suggests that a mechanical factor (joint motion between the acetabulum and the outer head) and the prosthetic design (smooth surface of the unfixed outer head) as well as biological reactions to debris may be important in massive acetabular osteolysis and progressive migration of the outer head.

No benefits in any form have been received or will be received from a commercial party related directly or indirectly to the subject of this article.

\section{REFERENCES}

1. Bateman JE. Single-assembly total hip prosthesis: preliminary report. Orthop Dig 1974;2:15-22.

2. Giliberty RP. A new concept of a bipolar endoprosthesis. Orthop Rev 1974;III:40-5.

3. Phillips TW. The Bateman bipolar femoral head replacement: a fluoroscopic study of movement over a four-year period. J Bone Joint Surg [Br] 1987;69-B:761-4.

4. Phillips TW, Rao DR. Bateman bipolar hips with autologous bone graft reinforcement for dysplastic acetabula. Clin Orthop 1990;251: 104-12.

5. Yamamuro T, Ueo T, Okumura H, Iida H, Hamamoto T. Five-year results of bipolar arthroplasty with bone grafts and reamed acetabula for osteoarthritis in young adults. Clin Orthop 1990;251:75-81.

6. Bateman JE, Berenji AR, Bayne O, Greyson ND. Long-term results of bipolar arthroplasty in osteoarthritis of the hip. Clin Orthop 1990;251:54-66.

7. Bowman AJ Jr, Walker MW, Kilfoyle RM, O'Brien PI, McConville JF. Experience with the bipolar prosthesis in hip arthroplasty: a clinical study. Orthopedics 1985;8:460-7.
8. Cameron HU, Hood-Szivek P, Turner R. Femoral head migration after single assembly total hip arthroplasty. Clin Orthop 1982;164: 230-3.

9. Cameron HU, Cha EJ, Jung YB. An examination of factors contributing to failure of bipolar prostheses. Clin Orthop 1989;240:206-9.

10. Torisu T, Utsunomiya K, Maekawa M, Ueda Y. Use of bipolar hip arthroplasty in states of acetabular deficiency. Clin Orthop 1990;251: 119-25.

11. Torisu T, Izumi H, Fujikawa Y, Masumi S. Bipolar hip arthroplasty without acetabular bone-grafting for dysplastic osteoarthritis: results after 6-9 years. J Arthroplasty 1995;10:15-27.

12. Nakata K, Ohzono K, Hiroshima K. Progressive migration in bipolar arthroplasty for osteoarthritis of the hip secondary to congenital dislocation. Clin Orthop 1994;304:156-64.

13. Bose WJ, Miller GJ, Petty W. Osteolysis of the acetabulum associated with a bipolar hemiarthroplasty. J Bone Joint Surg [Am] 1995; 77-A:1733-5.

14. Merle d'Aubigné R, Postel M. Functional results of hip arthroplasty with acrylic prosthesis. J Bone Joint Surg [Am] 1954;36-A:451-75.

15. Harris WH, McCarthy JC Jr, O'Neill DA. Femoral component loosening using contemporary techniques of femoral cement fixation. J Bone Joint Surg [Am] 1982;64-A:1063-7.

16. Mulroy RD Jr, Harris WH. The effect of improved cementing techniques on component loosening in total hip replacement: an 11-year radiographic review. J Bone Joint Surg [Br] 1990;72-B: 757-60.

17. Callaghan JJ, Salvati EA, Pellicci PM, Wilson PD Jr, Ranawat CS. Results of revision for mechanical failure after cemented total hip replacement, 1979 to 1982: a two- to five-year follow-up. J Bone Joint Surg [Am] 1985;67-A:1074-85.

18. Callaghan JJ, Dysart SH, Savory CG. The uncemented porouscoated anatomic total hip prosthesis: two year results of a prospective consecutive series. J Bone Joint Surg [Am] 1988;70-A:337-46.

19. Izumi H, Torisu T, Itonaga I, Masumi S. Joint motion of bipolar femoral prostheses. J Arthroplasty 1995;10:237-43.

20. Nishii T, Sugano N, Masuhara K, Takaoka K. Bipolar cup design may lead to osteolysis around the uncemented femoral component. Clin Orthop 1995;316:112-20. 